\section{RMD Open}

Rheumatic \& Musculoskeletal Diseases

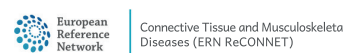

\title{
Idiopathic inflammatory myopathies: state of the art on clinical practice guidelines
}

Alain Meyer, ${ }^{\oplus 1,2}$ Carlo Alberto Scirè, ${ }^{\circledR 3}$ Rosaria Talarico, ${ }^{4}$ Tobias Alexander, ${ }^{\odot 5}$ Zahir Amoura, ${ }^{6}$ Tadej Avcin, ${ }^{7}$ Simone Barsotti, ${ }^{8,9}$ Lorenzo Beretta, ${ }^{\odot} 10$ Jelena Blagojevic, ${ }^{11}$ Gerd Burmester, ${ }^{5}$ Ilaria Cavazzana, ${ }^{12}$ Patrick Cherrin, ${ }^{6}$ Laura Damian, ${ }^{13}$ Andrea Doria, ${ }^{14}$ João Eurico Fonseca, ${ }^{15}$ Federica Furini, ${ }^{16}$ Ilaria Galetti, ${ }^{17}$ Frederic Houssiau, ${ }^{18}$ Thomas Krieg, ${ }^{19}$ Maddalena Larosa, ${ }^{14}$ David Launay, ${ }^{20}$ Raquel Campanilho-Marques, ${ }^{15}$ Thierry Martin, ${ }^{21}$ Marco Matucci-Cerinic, ${ }^{11}$ Pia Moinzadeh, ${ }^{19}$ Carlomaurizio Montecucco, ${ }^{22}$ Maria Francisca Moraes-Fontes, ${ }^{\circ 3}$ Luc Mouthon, ${ }^{24}$ Rossella Neri, ${ }^{4}$ Sabrina Paolino, ${ }^{25}$ Yves Piette, ${ }^{26}$ Simona Rednic, ${ }^{13}$ Farah Tamirou, ${ }^{18}$ Angela Tincani, ${ }^{12}$ Natasa Toplak, ${ }^{7}$ Stefano Bombardieri, ${ }^{27}$ Eric Hachulla, ${ }^{20}$ Ulf Mueller-Ladner, ${ }^{28}$ Matthias Schneider, ${ }^{29}$ Vanessa Smith, ${ }^{26}$ Ana Vieira, ${ }^{30}$ Maurizio Cutolo, ${ }^{25}$ Marta Mosca, ${ }^{4,8}$ Lorenzo Cavagna ${ }^{22}$

To cite: Meyer $A$, Scirè $C A$, Talarico R, et al. Idiopathic inflammatory myopathies: state of the art on clinical practice guidelines. RMD Open 2019;4:e000784. doi:10.1136/ rmdopen-2018-000784

\section{- Prepublication history for this paper is available online. To view these files, please visit the journal online (http://dx.doi. org/10.1136/rmdopen-2018- 000784).}

Received 4 August 2018 Revised 7 January 2019 Accepted 8 January 2019

Check for updates

(c) Author(s) (or their employer(s)) 2019. Re-use permitted under CC BY-NC. No commercial re-use. See rights and permissions. Published by BMJ.

For numbered affiliations see end of article.

Correspondence to Dr Alain Meyer; alain.meyer7@gmail.com

\section{ABSTRACT}

Idiopathic inflammatory myopathies (IIMs) encompass a heterogeneous group of rare autoimmune diseases characterised by muscle weakness and inflammation, but in antisynthetase syndrome arthritis and interstitial lung disease are more frequent and often inaugurate the disease. Clinical practice guidelines (CPGs) have been proposed for IIMs, but they are sparse and heterogeneous. This work aimed at identifying: i) current available CPGs for IIMs, ii) patients' and clinicians' unmet needs not covered by CPGs. It has been performed in the framework of the European Reference Network on rare and complex connective tissue and musculoskeletal diseases (ReCONNET), a network of centre of expertise and patients funded by the European Union's Health Programme. Fourteen original CPGs were identified, notably recommending that: i) extra-muscular involvements should be assessed; ii) corticosteroids and methotrexate or azathioprine are first-line therapies of IIMs. iii) IVIG is a treatment of resistantDM that may be also used in other resistant-IIMs; iv) physical therapy and sun protection (in DM patients) are part of the treatment; v) tumour screening for patients with DM include imaging of chest, abdomen, pelvis and breast (in woman) along with colonoscopy (in patients over 50 years); vi) disease activity and damages should be monitor using standardised and validated tools. Yet, only half of these CPGs were evidence-based. Crucial unmet needs were identified both by patients and clinicians. In particular, there was a lack of large multidisciplinary working group and of patients' preferences. The following fields were not or inappropriately targeted: diagnosis; management of extra-muscular involvements other than skin; co-morbidities and severe manifestations.

\section{Key messages}

What is already known about this subject?

- Clinical practice guidelines (CPGs) have been proposed for idiopathic inflammatory myopathies (IIMs) but no review of "what we have" and patients' as well as clinicians' unmet needs has been performed so far.

What does this study add?

- Fourteen original CPGs were identified, covering important issues. Yet, only half of these CPGs were evidence-based. and crucial unmet needs were identified both by patients and clinicians.

How might this impact on clinical practice?

- Future CPGs should include multidisciplinary stakeholders, together with patients, to address the identified unmet needs in myositis care, based on growing evidence in the field.

\section{INTRODUCTION}

Idiopathic inflammatory myopathies (IIMs) encompass a heterogeneous group of rare autoimmune diseases showing a large degree of overlap ${ }^{1}$ but also some peculiarities and differences, in particular in the setting of antisynthetase syndrome (ASSD). ${ }^{2}$ If IIMs affect adults and children, ASSD is generally an adultonset condition, ${ }^{3}$ with only few cases reported in paediatric age. ${ }^{4}$ IIMs are generally characterised by the occurrence of muscle weakness and inflammation, but in ASSD, arthritis and interstitial lung disease (ILD) are more frequently 
observed and frequently represent the first manifestation of the disease. ${ }^{5}$ Skin can also be frequently affected by IIMs, with occurrence of lesions such as heliotrope rash, Gottron's sign/papules, skin ulcers, V-sign, Shawl sign, Hiker's feet and mechanic's hands, with these two latter considered as typical ASSD findings. ${ }^{6} 7$ Additionally, IIMs are associated with cancer, ${ }^{8}$ the risk of which is increased up to 5.3-fold with respect to general population in males with dermatomyositis (DM). ${ }^{9}$ Thus, physicians from different specialties are involved in the care (including diagnosis, treatment and monitoring) of these patients. Even if IIMs are potentially treatable diseases, currently, mortality is hardly fourfold increased with respect to general population ${ }^{10}$ and quality of life is decreased. ${ }^{11}$ Considering the large number of specialists potentially involved in the daily management of these patients, as well as the different therapeutic approaches available, it is important to homogenise the different approaches, in order to establish a common shared strategy. Clinical practice guidelines (CPGs) are systematically developed statements to assist practitioner and patient decisions about appropriate healthcare for specific clinical circumstances. ${ }^{12} 13$ CPGs have been proposed for IIMs, but they are sparse and not homogeneous. This work attended to identify currently available CPGs for IIMs, to provide a narrative review of their contents and to identify patients' and clinicians' unmet needs. It has been performed in the framework of the European Reference Network on rare and complex connective tissue and musculoskeletal diseases (ERN ReCONNET), a Network of centre of expertise and patients funded by the European Union's Health Program (reconnet.ern-net.eu).

\section{METHODS}

\section{Objective and management of first work package of ERN ReCONNET}

The aim of the first work package of ERN ReCONNET was the identification of field of application of identified CPGs, looking for potential unmet needs.

Planning and evaluation of the work was driven by regular interaction between participants of the working group during meetings (European League Against Rheumatism (EULAR) Congress 2017, American College of Rheumatology (ACR) Congress 2017, ERN ReCONNET Meeting, Pisa, 4-6 February 2018), web conferences, electronic letters and ERN Collaborative Platform (https:// webgate.ec.europa.eu).

\section{Systematic literature search}

Between June 2017 and February 2018, we carried out a search in PUBMED and EMBASE based on controlled terms (MeSH and Emtree), keywords of the disease and publication type (CPGs). All published articles were reviewed in order to identify existing CPGs on diagnosis, monitoring and treatment of IIMs, according to the Institute of Medicine 2011 definition (clinical practice guidelines are statements that include recommendations intended to optimise patient care that are informed by a systematic review of evidence and an assessment of the benefits and harms of alternative care options).

The Disease Coordinators (DCs) (LC and AM) of the ERN ReCONNET for IIMs have assigned the work on CPGs to the Healthcare Providers involved. Moreover, in order to implement the list of guidelines provided by Medline and Embase search, the group performed also a hand search. A first screening of evidence-based medicine guidelines (regardless its level) was performed on the basis of their title and abstract (systematic search and hand search). A discussion group was set for the effective inclusion and evaluation of the existing CPGs, in order to identify the unmet needs.

Here is the search strategy: Medline (Pubmed): ("polymyositis" [MeSH Terms] OR "polymyositis" [All Fields] OR "dermatomyositis" [MeSH Terms] OR "dermatomyositis" [All Fields] OR "myositis" [MeSH Terms] OR "myositis" [All Fields] OR ("idiopathic" [All Fields] AND "inflammatory" [All Fields] AND "myopathies" [All Fields]) OR "idiopathic inflammatory myopathies" [All Fields]) AND ("Practice Guideline" [Publication Type] OR "Practice Guidelines As Topic" [MeSH Terms] OR Practice Guideline [Publication Type] OR "Practice Guideline" [Text Word] OR "Practice Guidelines" [Text Word] OR "Guideline" [Publication Type] OR "Guidelines As Topic" [MeSH Terms] OR Guideline [Publication Type] OR "Guideline" [Text Word] OR "Guidelines" [Text Word] OR "Consensus Development Conference" [Publication Type] OR "Consensus Development Conferences As Topic" [MeSH Terms] OR "Consensus" [MeSH Terms] OR "Consensus" [Text Word] OR "Recommendation" [Text Word] OR "Recommendations" [Text Word] OR "Best Practice" [TextWord] OR "Best Practices" [TextWord]). Embase: ('myositis' / exp OR 'idiopathic inflammatory myopathy' OR 'inflammatory myopathy' OR 'muscle inflammation' OR 'myopathy, inflammatory' OR 'polymyositis' / exp OR 'fibromyositis' OR 'polymyositis' OR 'dermatomyositis' / exp OR 'dermatomyositides' OR 'dermatomyositis' OR 'polymyositis arthropathica') AND ('practice guideline'/exp OR 'practice guideline' OR 'practice guidelines'/exp OR 'practice guidelines' OR 'clinical practice guideline'/exp OR 'clinical practice guideline' OR 'clinical practice guidelines'/exp OR 'clinical practice guidelines' OR 'clinical practice guidelines as topic'/exp OR 'clinical practice guidelines as topic' OR 'guideline'/exp OR 'guideline' OR 'guidelines'/ exp OR 'guidelines' OR 'guidelines as topic'/exp OR 'guidelines as topic' OR 'consensus development' / exp OR 'consensus development' OR 'consensus development conference'/exp OR 'consensus development conference' OR 'consensus development conferences' / exp OR 'consensus development conferences' OR 'consensus development conferences as topic'/exp OR 'consensus development conferences as topic' OR 'consensus'/exp OR 'consensus' OR 'recommendation' OR 'recommendations') AND [embase]/lim NOT [medline]/lim. 
Inclusion criteria and CPGs identification

CPGs were included if ${ }^{12} 13$ :

i. Their development was aimed at assisting practitioners' and patients' decisions about appropriate healthcare for patients with IIMs and ASSD.

ii. They were based on a systematic review of evidence. iii. They were written in English.

All papers identified during the literature search were screened for eligibility by two evaluators and by DCs based on title and abstract assessment. Only papers considered eligible by at least one evaluator were included. Papers selected after the first round were then further assessed in order to verify their actual status of CPGs. In case of disagreement in the decision, a further round of discussion involving participants has been performed, in order to uniform the evaluation reaching the $100 \%$ of consensus.

Physicians' and patients' unmet needs were delineated by focus groups conducted during the ERN meeting followed by written exchange during the redaction process of the present manuscript. Patients were a 51-year-old woman with bachelor's degree, a 45-year-old man with bachelor's degree and a 39-year-old woman with higher level of education.

\section{RESULTS: STATE OF THE ART ON CPGS Identification of existing CPGs}

The systematic literature search provided a total of 727 citations. Title and abstract evaluation identified 98 papers suitable for full-text upload and review. After fulltext revision, we identified 14 original papers published between 1996 and 2017 $7^{14-32}$ (figure 1).

In the following sections, these papers will be thus defined as CPGs for practical purpose.

This is the first review providing an overview of currently available CPGs for IIMs whose characteristics and contents are resumed below and in tables 1 and 2 .

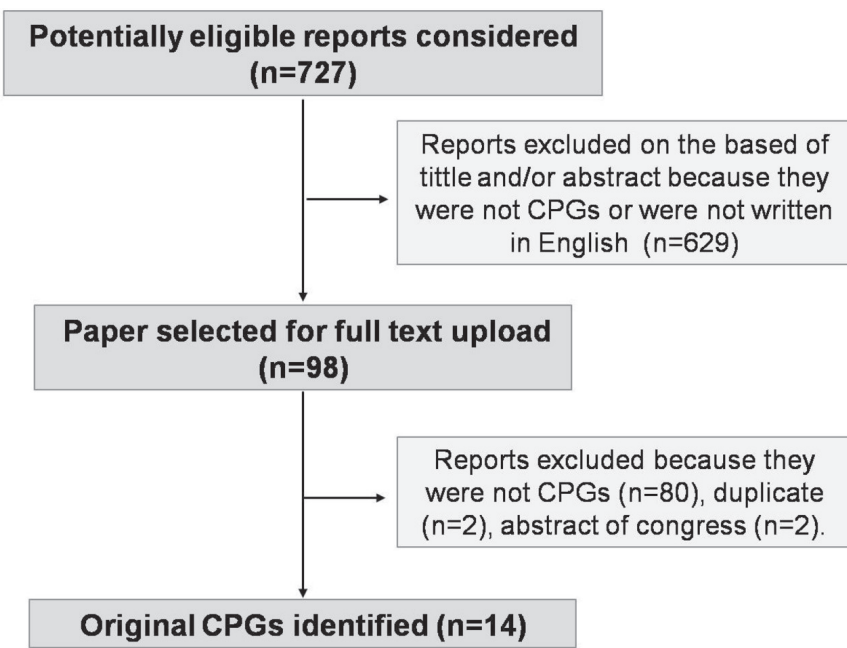

Figure 1 Flow chart constructed from Pubmed, Embase and national databases. CPGs, clinical practice guidelines.

\section{CPGS CHARACTERISTICS}

CPGs were written (first and/or last authors) by rheumatologists $(n=3)$, neurologists $(n=7)$, dermatologists $(n=3)$ and pulmonologists $(n=1)$. In four CPGs, co-workers from different specialties than main authors were also involved. No CPGs involved clinicians from more than two different specialties. No CPGs involved patients.

Five CPGs were dedicated to IIMs, while nine covered a broader spectrum of diseases (including IIMs).

Nine CPGs targeted IIMs as a whole (juvenile and adult) although in four of the latter, ${ }^{14-16}{ }^{23}$ authors did not state whether the recommendation applied to adult and/or juvenile IM. One paper targeted specifically juvenile IIMs and four specifically adults IIMs.

The majority of CPGs $(n=13)$ focused on therapeutic questions including overall treatment, use of intravenous globulin, management of lung and cutaneous disease. Others addressed disease measurements (tools for clinical assessment and improvement definition), associated conditions (cancer, pregnancy) and overall management. In seven CPGs, evidence was systematically searched and discussed (evidence-based CPGs). In the others, the method for evidence search was not provided ('eminence-based' CPGs). There were no specific recommendations focusing on ASSD.

\section{CPGS CONTENT}

The covered points are as follows. (1) Global management of juvenile dermatomyositis (DM), the most frequent IIMs in children, ${ }^{20}$ and of IIMs in general. ${ }^{19} 2331$ (2) The role of physical therapy in IIMs, focusing on the evaluation of disease-specific quality indicators, outcome measures and guidelines. The establishment of a physical rehabilitation path, in association to the pharmacological treatments, is crucial to obtain the best improvement possible in these patients. ${ }^{15}$ (3) Screening of cancer, one of the leading causes of death in IIMs. ${ }^{32}$ (4) Use of intravenous immunoglobulin (IVIG), an expensive treatment that should be reserved only to specific clinical conditions. ${ }^{1416172129}$ (5) Cutaneous manifestations which are debilitating complications of various IIMs,${ }^{22}$ in particular in juvenile forms. ${ }^{20}$ (6) ILD-related treatment, ${ }^{28}$ the main impacting prognostic factor in IIMs in general and in ASSD in particular. (7) Pregnancy planning and management, in a field in which juvenile forms are common and young people in childbearing age can be affected by these diseases. ${ }^{18}$

Recommendations of available CPGs are presented in table 2 and notably stated that: (1) extramuscular involvements should be assessed; (2) corticosteroids and methotrexate or azathioprine are first-line therapies of IIMs; (3) IVIG is a treatment of resistant-DM that may be also used in other resistant-IIMs; (4) physical therapy and sun protection (in patients with DM) are part of the treatment; (5) tumour screening for patients with DM include imaging of chest, abdomen, pelvis and breast (in woman) along with colonoscopy (in patients over 50 years); (6) 
Table 1 CPGs general characteristics

\begin{tabular}{|c|c|c|c|c|c|c|}
\hline Author & Date & Target & $\begin{array}{l}\text { Main authors } \\
\text { specialty }\end{array}$ & $\begin{array}{l}\text { Other specialty } \\
\text { involved }\end{array}$ & Based on & Scope \\
\hline Drake et $a l^{19}$ & 1996 & IIMs as a whole & Dermatology & None & $\begin{array}{l}\text { Evidence } \\
\text { (grade C-D) }\end{array}$ & Treatment (overall) \\
\hline Bril et al ${ }^{16}$ & 1999 & IIMs as a whole & Neurology & None & Eminence & Treatment (IVIG) \\
\hline Doria et $a l^{18}$ & 2004 & Adult IIMs & Rheumatology & Neurology & Eminence & Pregnancy \\
\hline Feasby et $a l^{21}$ & 2007 & IIMs as a whole & Neurology & None & $\begin{array}{l}\text { Evidence } \\
\text { (grade B-D) }\end{array}$ & Treatment (IVIG) \\
\hline $\begin{array}{l}\text { Alexanderson et } \\
\text { al }{ }^{15}\end{array}$ & 2007 & IIMs as a whole & Rheumatology & Physical therapy & Eminence & Disease measurement (tools) \\
\hline Donofrio et $a l^{17}$ & 2009 & Adult IIMs & Neurology & None & $\begin{array}{l}\text { Evidence } \\
\text { (grade B-D) }\end{array}$ & Treatment (IVIG) \\
\hline Hengstman et $a^{23}$ & 2009 & IIMs as a whole & Neurology & None & Eminence & Treatment (overall) \\
\hline Titulaer et $a l^{\beta 2}$ & 2011 & IIMs as a whole & Neurology & None & $\begin{array}{l}\text { Evidence } \\
\text { (grade C-D) }\end{array}$ & Tumour screening \\
\hline Patwa et $\left.a\right|^{29}$ & 2012 & Adult IIMs & Neurology & None & $\begin{array}{l}\text { Evidence } \\
\text { (grade B-D) }\end{array}$ & Treatment (IVIG) \\
\hline $\begin{array}{l}\text { Sunderkotter et } \\
\left.a\right|^{31}\end{array}$ & 2016 & IIMs as a whole & Neurology & Dermatologist & Eminence & General management \\
\hline Enk et $a^{14}$ & 2016 & IIMs as a whole & Dermatology & None & Eminence & Treatment (IVIG) \\
\hline Fujimoto et $a^{22}$ & 2016 & IIMs as a whole & Dermatology & None & $\begin{array}{l}\text { Evidence } \\
\text { (grade C-D) }\end{array}$ & Treatment (skin disease) \\
\hline Morrisset et $\left.a\right|^{28}$ & 2016 & Adult IIMs & Pneumology & None & Eminence & Lung disease \\
\hline Enders et $\left.a\right|^{20}$ & 2017 & Juvenile IIMs & Rheumatology & None & $\begin{array}{l}\text { Evidence } \\
\text { (grade B-D) }\end{array}$ & General management \\
\hline
\end{tabular}

Evidence was graded according to Grading of Recommendations Assessment, Development and Evaluation Working Group 2007 (http://www. gradeworkinggroup.org/)

CPG: clinical practice guideline;IIM: idiopathic inflammatory myopathy; IVIG: intravenous immunoglobulin;

disease activity and damages should be monitored using standardised and validated tools.

\section{UNMET NEEDS}

CPGs that are currently available do not cover the entire spectrum of IIMs needs. From the clinical point of view, we think that the identification of uncovered areas could be useful for the establishment of additional CPGs. From the scientific point of view, by considering that CPGs are recommendations based on scientific evidences, some of the unmet needs could indicate areas that deserve future research. Finally, it will be important to critically review the content of existing CPGs, in order to identify their strength and weakness, looking to their improvement, as planned in the next ReCONNET work packages.

\section{Clinicians' unmet needs}

Even if several issues have been addressed, other relevant points are currently not or ineffectively targeted by CPGs IIMs that can be summarised as follows (table 3):

Unmet needs related to the stakeholders of CPGs development

- The lack of large multidisciplinary working group is the first transversal and crucial problem of available CPGs. Indeed, considering that patients with IIMs have multiorgan involvement with different manifestations prevalence and severity levels, CPG for their optimal management cannot be developed without a larger number of different organ specialists as stakeholders. In this regard, a collaboration of ReCONNET with other ERNs concern by IIMs (EURO-NMD and ERN LUNG) has been planned.

- Second, as IIMs are chronic diseases, patients' perspective is mandatory for the improvement of daily quality of care. This issue will be overcome by initiatives notably started by the OMERACT (independent initiative of international health professionals interested in outcome measures in rheumatology). ${ }^{33}$

Unmet needs related to scope and target of the CPGs

- No CPGs are currently available for diagnosis. Early intervention may be associated with a better outcome $^{34}$ but treatment is often delayed or not appropriated, because IIMs can be misdiagnosed as numerous other conditions including non-inflammatory myopathies ${ }^{34}$ and other inflammatory diseases (such as rheumatoid arthritis ${ }^{35}$ or ILDs with autoimmune features ${ }^{36}$ ). On the other hand, mimickers of treatable IIMs include numerous non-inflammatory myopathies and inclusion body myositis. ${ }^{37}$ Although being an important milestone in the field, the recently published EULAR/ACR IIMs classification criteria did not match the definition of CPGs and were thus not included in this review. Yet, even considering 
Table 2 Scope and key recommendations of available CPGs for IIMs

\begin{tabular}{|c|c|c|}
\hline Scope & $\begin{array}{l}\text { First author, date of } \\
\text { publication (ref) }\end{array}$ & Key recommendations of the CPG \\
\hline \multirow[t]{2}{*}{ General management } & Sunderkotter, $2016^{31}$ & $\begin{array}{l}\text { All patients with IIMs should undergo a pulmonary function test and-in case of } \\
\text { pathological findings - further pulmonology workup. } \\
\text { Tumour screening in DM with anti-TIF1- } \gamma \text { include 18-fluoro-deoxyglucose-positron } \\
\text { emission tomography/CT or CT of the thorax and abdomen in combination with a } \\
\text { gynaecological/urological examination is recommended (no strategy is provided in } \\
\text { other case by the CPG). } \\
\text { Treatment of IIMs includes: } \\
\text { - CS (intravenous if severe, oral if not). } \\
- \text { AZA (for adult) and MTX (for children) when: (1) severe IIMs, (2) impossibility to } \\
\text { reduce CS dosage below the 'Cushing threshold' after } 3 \text { months. } \\
\text { - IVIG is recommended in patients unresponsive to CS+AZA. } \\
\text { - Non-pharmacological measures: regular physical therapy, sun protection (for } \\
\text { patients with DM). }\end{array}$ \\
\hline & Enders, $2017^{20}$ & $\begin{array}{l}\text { All children with suspected IIMs should be referred to a specialised centre. High-risk } \\
\text { patients (as defined in the CPG) need immediate/urgent referral. } \\
\text { Assessment of organ involvement (muscle, skin, lung, heart), calcinosis and } \\
\text { antibodies (see CPG for details) is recommended for all children with IIMs. } \\
\text { Disease activity, damages and health status should be monitored in a standardised } \\
\text { way. } \\
\text { Juvenile IIMs treatment includes: } \\
\text { - Sun protection, exercise programme. } \\
\text { - First line: high-dose CS and MTX. } \\
\text { - If failure (considered within the first } 12 \text { weeks): topical TACRO/ CS (if localised } \\
\quad \text { skin disease), CsA or MMF (if intolerance to MTX), IVIG as adjunct or RTX as } \\
\quad \text { adjunct or CYC or antitumour necrosis factor therapies (if resistance). }\end{array}$ \\
\hline
\end{tabular}

Treatment (overall) Drake, $1996^{19}$

- Non-pharmacological treatments of IIMs include physical therapy, photoprotection and adequate nutrition.

- Pharmacological treatments of IIMs include CS (topical and systemic); antimalarial and CS-sparing agents (no limitative list provided in the CPG).

- Calcinosis treatments include medical (diphosphonates, aluminium hydroxide, probenecid, colchicine and low-dose warfarin) and surgical management.

Hengstman, $2009^{23}$ First line of IIMs is prednisone $(1 \mathrm{mg} / \mathrm{kg})$ and AZA or MTX.

- Second line, in case of severe pulmonary involvement, is CsA or TACRO or CYC.

- Second line, in case of no severe pulmonary involvement, is IVIG.

- Third line is RTX or TACRO or MMF or CsA or CYC.

\begin{tabular}{|c|c|c|}
\hline \multirow[t]{4}{*}{ Treatment (IVIG) } & Bril, $1999^{16}$ & $\begin{array}{l}\text { IVIG is favourably recommended for the treatment of DM and recommended as a last } \\
\text { resort for the other IIMs. }\end{array}$ \\
\hline & Feasby, $2007^{21}$ & $\begin{array}{l}\text { IVIG is recommended as an adjunctive treatment for DM who did not adequately } \\
\text { respond to other immunosuppressant medications (such as CS, MTX or AZA). } \\
\text { IVIG may be considered as an adjunctive treatment option for PM who failed to } \\
\text { respond to first-line therapies. } \\
\text { IVIG is not recommended for IBM. }\end{array}$ \\
\hline & Donofrio, $2009^{17}$ & $\begin{array}{l}\text { IVIG therapy is recommended as add-on treatment in refractory IIMs. } \\
\text { IVIG is not recommended for IBM. }\end{array}$ \\
\hline & Enk, $2016^{14}$ & $\begin{array}{l}\text { Severe forms of DM, PM and IBM are considered by the authors as indication of IVIG, } \\
\text { as first-line treatment (in fulminant course, severe myolysis or paralysis) or second-line } \\
\text { treatment (in other cases), with continuation of immunosuppressive therapy. }\end{array}$ \\
\hline Pregnancy & Doria, $2004^{18}$ & $\begin{array}{l}\text { Patients with IIMs should be correctly informed on the risk of becoming pregnant. } \\
\text { Pregnancies should be planned when IIMs is in remission } \\
\text { Patients with IIMs should be regularly monitored during gestation and postpartum by } \\
\text { a multidisciplinary team. } \\
\text { In the case of disease relapse, treatment has to be started as soon as possible. } \\
\text { IIMs treatment in pregnant patients is: CS ( } 1 \mathrm{mg} / \mathrm{kg} / \text { day until thenormalisation of } \\
\text { serum creatine kinase levels). If insufficient response: CsA, AZA, plasma exchange or } \\
\text { IVIG. }\end{array}$ \\
\hline
\end{tabular}

Continued 
Table 2 Continued

\begin{tabular}{|c|c|c|}
\hline Scope & $\begin{array}{l}\text { First author, date of } \\
\text { publication (ref) }\end{array}$ & Key recommendations of the CPG \\
\hline $\begin{array}{l}\text { Disease measurement } \\
\text { (tools) }\end{array}$ & Alexanderson, $2007^{15}$ & $\begin{array}{l}\text { Disease activity and disability should be measured at disease onset, at 3, } 6 \text { and } 12 \\
\text { months, and then at least once a year. } \\
\text { Only valid and reliable clinical outcome measures should be used (such clinical } \\
\text { outcome measures were not available at the time of the publication of the CPG). }\end{array}$ \\
\hline Tumour screening & Titulaer, $2011^{32}$ & $\begin{array}{l}\text { Patients with DM should have CT-thorax/abdomen, ultrasound of the pelvic region } \\
\text { and mammography in women, ultrasound of testes in men under } 50 \text { years and } \\
\text { colonoscopy in men and women over } 50 \text {. } \\
\text { If primary screening is negative, repeat screening after } 3-6 \text { months and screen every } \\
6 \text { months up till } 4 \text { years. }\end{array}$ \\
\hline $\begin{array}{l}\text { Extramuscular } \\
\text { involvement (skin) }\end{array}$ & Fujimoto, $2016^{22}$ & $\begin{array}{l}\text { For calcinosis in IIMs: low-dose warfarin, aluminium hydroxide gel, diltiazem } \\
\text { hydrochloride, probenecid or bisphosphonate are recommended as an option. } \\
\text { Surgical treatment is also recommended as an option. } \\
\text { For panniculitis in IIMs: CS is recommended. If no response, immunosuppressants } \\
\text { such as CsA, MTX and AZA are recommended as an option. }\end{array}$ \\
\hline $\begin{array}{l}\text { Extramuscular } \\
\text { involvement (lung) }\end{array}$ & Morrisset, $2016^{28 *}$ & $\begin{array}{l}\text { In acute or severe IIMs-ILD: high-dose steroids+CYC or RTX or CsA or TACRO is } \\
\text { recommended. } \\
\text { In chronic or mild to moderate IIMs-ILD: steroids+MMF or AZA is recommended. } \\
\text { In case of failure: it is recommended to switch agent or consider combination of } \\
\text { agents, or consider IVIG or consider transplantation referral. }\end{array}$ \\
\hline
\end{tabular}

AZA, azathioprine; CPGs, clinical practice guidelines; CS, corticosteriod; CYC, cyclophosphamide; CsA, ciclosporin A; DM, dermatomyositis; IBM, inclusion body myositis; IIM: idiopathic inflammatory myopathy; ILD: interstitial lung disease; IVIG, intravenous immunoglobulin; MMF, mycophenolate mofetil; MTX, methotrexate; PM, polymyositis; RTX, rituximab; TACRO, tacrolimus.

these classification criteria, ${ }^{38}$ lung, joint and skin (other than DM rash) involvements are not taken into account, ${ }^{39}$ which is an issue especially for diagnosis of ASSD, as previously suggested by the American, European NEtwork of Antisynthetase Syndrome collaborative group. ${ }^{236}{ }^{39-41}$ This unmet need will be fixed in next year thanks to CLASS project addressed to the establishment of next EULAR/ACR classification criteria of ASSD.
- Management of extramuscular organ involvement other than skin is not appropriately targeted by current available CPGs. Of note, four papers address this important point, but have not been included in this review as they are based on expert consensus and thus do not match criteria for CPGs. ${ }^{24-27}$ Lung disease, one of the most frequent manifestations of IIMs and major cause of death ${ }^{10}$ is only addressed by one $\mathrm{CPG}^{28}$ No CPG currently address heart, joints

Table 3 Synthesis of the physicians' unmet needs

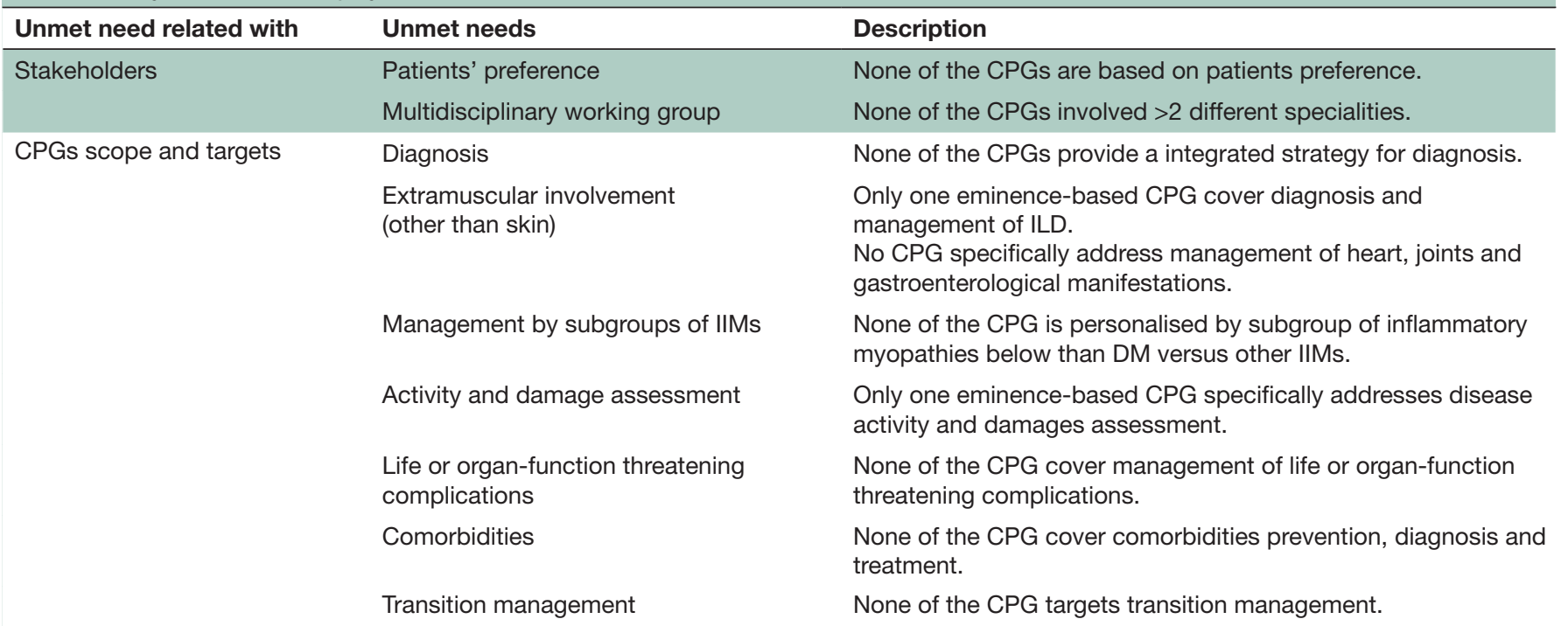

CPGs, clinical practice guidelines; DM, dermatomyositis; IIM: idiopathic inflammatory myopathy; ILD: interstitial lung disease. 
and gastroenterological manifestations, which are yet source of handicap and/or increased mortality. ${ }^{42-44}$

- IIMs are a heterogeneous group of diseases. The clinical manifestations, autoantibody profile and muscle histology can be used to distinguish patient subgroups (extending their spectrum far beyond the subdivision between DM and other IIMs) with fairly homogeneous patterns of complications, treatment responses and outcomes. Yet, none of the CPGs identified in this review were specifically dedicated to one of these subgroups.

- Accurate monitoring of muscle inflammatory activity and damages are mandatory in order to meet the subtle threshold point between undertreatment and overtreatment. This challenge has been taken up by only one CPG. The recently published EULAR/ACR criteria for clinical response in adult and juvenile $\mathrm{IIMs}^{4546}$ is an important step in this field. Yet, they were not included in this review because they did not match the definition of CPGs.

- Patients with IIMs may face life or organ-function threatening complications such as severe rapidly progressive ILD, myocarditis, pneumomediastinum, pulmonary hypertension, respiratory failure, prone position complication due to severe muscle weakness dysphagia and ischaemic ulcerative colitis. These situations require peculiarly prompt diagnosis and management. Yet, no CPG currently cover these points.

- Side-effects of IIMs treatments and comorbidities (such as infections, osteoporosis, cardiovascular events and high-risk pregnancy) are major causes of morbidity and mortality in patients with IIM. ${ }^{10}{ }^{47}$ Prevention and management of these associated conditions are currently not or only insufficiently targeted by CPGs.

- Transition management. IIMs encompass all ages with different disease phenotypes and different patients' needs, in particular in the transition period. Patients' approach of adult and paediatric clinicians is generally different, and this may be an additional serious problem to be considered.

\section{Patients' unmet needs}

This paragraph intends to highlight the unmet needs of the IIMs European community. The content of this paragraph has been carefully but hardly realised collecting the voices and the points of view of the patients affected by the disease. The rarity of the disease and the scarcity of patient organisations made this work harder than expected. IIMs spectrum disorders encompass a large number of conditions with a very heterogeneous range of manifestations, not limited to muscle involvement. On this basis, it is evident that patients' needs are very different and deeply influenced by disease presentation pattern. Furthermore, also the diagnosis is not always easy to reach and this adds further uncertainty to patients, with a large number of doubts about the carried disease: 'I do not understand what I have?', 'What is happening to me?', 'What should I expect from the future?'. Even if crucial, these questions have not always an answer in IIMs or, even worse, they have different answers according to the different referring specialist. Patients experience a lack of harmonisation in the medical approach and a scarce involvement in developing a common path. Being the diseases so heterogeneous, each patient would bring its own experiences and suggestions adding further useful information and improving the care of these conditions. Unfortunately, only few clinicians are aware that patients need more direct support and attention: a continuous process of discussion and dialogue with physicians could be surely relevant to this purpose. Furthermore, patients refer that they need more personalised assistance from the national health systems, in term of social demands and attention. The lack of harmonisation of assistance creates differences in the European Countries and ERN ReCONNET is perceived to possibly fill this gap.

\section{CONCLUSIONS}

We identified the currently IIMs available CPGs, showing a large area of unmet needs. A further effort is necessary and it has been planned by the ERN ReCONNET in order to evaluate the intrinsic validity and applicability of available recommendations. The standardisation and sharing of CPGs, from diagnosis to treatment, are crucial to really improve the prognosis of these patients. We need therefore to work intensively together with patients focusing on the global improvement of their daily life that represents a shared objective of patients and clinicians. We propose that future CPGs should include multidisciplinary stakeholders, together with patients, to address the identified unmet needs in myositis care, based on growing evidences.

\section{Author affiliations}

${ }^{1}$ Centre National de Référence des Maladies Systémiques et Auto-immunes Rares Grand-Est Sud-Ouest (RES0), Service de humatologie, Service de physiologie, Unité d'explorations fonctionnelles musculaires, Hôpitaux Universitaires de Strasbourg, Strasbourg, France

${ }^{2}$ EA3072, Fédération de Médecine Translationelle, Université de Strasbourg, Strasbourg, France

${ }^{3}$ Section of Rheumatology, Department of Medical Sciences, University of Ferrara Ferrara, Italy

${ }^{4}$ Rheumatology Unit, AOU Pisana, Pisa, Italy

${ }^{5}$ Department of Rheumatology and Clinical Immunology, Charité University Hospital Berlin, Berlin, Germany

${ }^{6}$ Department of Internal Medicine, Hospital Pitié-Salpêtrière, Assistance PubliqueHôpitaux de Paris, Paris, France

${ }^{7}$ Department of Allergology, Rheumatology and Clinical Immunology, University

Children's Hospital, University Medical Centre Ljubljana, Ljubljana, Slovenia

${ }^{8}$ Rheumatology Unit, University of Pisa, Pisa, Italy

${ }^{9}$ Department of Medical Biotechnology, University of Siena, Siena, Italy

${ }^{10}$ Referral Center for Systemic Autoimmue Diseases, Referral Center for Systemic Autoimmue DiseasesFondazione IRCCS Ca' Granda Ospedale Maggiore Policlinico di Milano, Milan, Italy

${ }^{11}$ Department of Clinical and Experimental Medicine, Department of Geriatric Medicine, Division of Rheumatology and Scleroderma Unit, University of Florence, AOUC, Florence, Italy 
${ }^{12}$ Rheumatology and Clinical Immunology Unit, Civil Hospital, Brescia, Italy

${ }^{13}$ Department of Rheumatology, Emergency County Teaching Hospital, Cluj-Napoca, Romania

${ }^{14}$ Rheumatology Unit, Department of Medicine, AO Padova and University of Padua, Padua, Italy

${ }^{15}$ Rheumatology Department, Hospital de Santa Maria, Centro Hospitalar Lisboa

Norte, Lisbon Academic Medical Centre, Lisbon, Portugal

${ }^{16}$ Section of Rheumatology, Department of Medical Sciences, Sant'Anna University Hospital, Ferrara, Italy

${ }^{17}$ FESCA, Federation of European Scleroderma Associations, Milan, Italy

${ }^{18}$ Department of Rheumatology, Cliniques Universitaires Saint-Luc, Université

Catholique de Louvain, Louvain-la-Neuve, Belgium

${ }^{19}$ Department of Dermatology, Universitätsklinikum Köln, Cologne, Germany

${ }^{20}$ Département de Médecine Interne et Immunologie Clinique, Centre de Référence des Maladies Systémiques et Auto-Immunes Rares du Nord-Ouest (CERAINO), Université de Lille, CHU Lille, LIRIC, INSERM, Lille, France

${ }^{21}$ Departement of Internal Medicine, Centre National de Référence des Maladies Systémiques et Auto-immunes Rares Grand-Est Sud-Ouest (RESO), Hôpitaux Universitaires de Strasbourg, France, Strasbourg, France

${ }^{22}$ Division of Rheumatology, University and IRCCS Policlinico S. Matteo Foundation, Pavia, Italy

${ }^{23}$ Unidade de Doenças Auto-imunes/Medicina 7.2, Hospital de Curry Cabral, Centro Hospitalar de Lisboa Central, Lisbon, Portugal

${ }^{24}$ Service de Médecine Interne, Centre de Référence Maladies systémiques Autoimmunes Rares d'lle de France, Assistance Publique-Hôpitaux de Paris (APHP), Hôpital Cochin, Université Paris Descartes, Paris, France

${ }^{25}$ Research Laboratory and Academic Division of Clinical Rheumatology, Department of Internal Medicine, IRCCS Polyclinic Hospital San Martino, University of Genoa, Genoa, Italy

${ }^{26}$ Department of Rheumatology, Department of Internal Medicine, Ghent University Hospital, Ghent University, Ghent, Belgium

${ }^{27}$ University of Pisa, Pisa, Italy

${ }^{28}$ Department of Rheumatology and Clinical Immunology, Kerckhoff Klinik, JustusLiebig University of Giessen, Bad Nauheim, Germany

${ }^{29}$ Department of Rheumatology, Universitätsklinikum Düsseldorf, Düsseldorf, Germany

${ }^{30}$ Liga Portuguesa Contra as Doenças Reumáticas, Núcleo Síndrome de Sjögren, Lisbon, Portugal

Acknowledgements Thanks to all the members of the Steering Committee of the ERN ReCONNET for the huge commitment during this work. A special thank goes to all the members of the ERN ReCONNET team for providing support during all the phases of the Work Package 3.

Contributors AM, SCA,TR, CM, MM and LC contributed to the conception and design of the work, acquisition of data, drafting the work and revising it critically for important intellectual content. All authors contributed to the analysis and interpretation of data, final approval of the version to be published and agreed to be accountable for all aspects of the work in ensuring that questions related to the accuracy or integrity of any part of the work are appropriately investigated and resolved.

Funding This publication was funded by the European Union's Health Programme (2014-2020), Framework Partnership Agreement number: 739531 - ERN ReCONNET. The content of this publication represents the views of the authors only and it is their sole responsibility; it cannot be considered to reflect the views of the European Commission and/or the Consumers, Health, Agriculture and Food Executive Agency (CHAFEA) or any other body of the European Union. The European Commission and the Agency do not accept any responsibility for use that may be made of the information it contains.

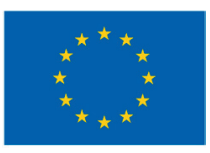

Disclaimer ERN ReCONNET is one of the 24 European Reference Networks (ERNs) approved by the ERN Board of Member States. The ERNs are co-funded by the European Commission. The content of this publication represents the views of the authors only and it is their sole responsibility; it cannot be considered to reflect the views of the European Commission and/or the Consumers, Health, Agriculture and Food Executive Agency (CHAFEA) or any other body of the European Union. The European Commission and the Agency do not accept any responsibility for use that may be made of the information it contains.

Competing interests None declared.

Patient consent for publication Not required.
Data sharing statement No additional data are available.

Open access This is an open access article distributed in accordance with the Creative Commons Attribution Non Commercial (CC BY-NC 4.0) license, which permits others to distribute, remix, adapt, build upon this work non-commercially, and license their derivative works on different terms, provided the original work is properly cited, appropriate credit is given, any changes made indicated, and the use is non-commercial. See: http://creativecommons.org/licenses/by-nc/4.0/.

\section{REFERENCES}

1. Meyer A, Lannes B, Goetz J, et al. Inflammatory myopathies: a new landscape. Joint Bone Spine 2018;85:23-33.

2. MontiS, MontecuccoC, CavagnaL. Clinical spectrum of anti-Jo-1associated disease. Curr Opin Rheumatol 2017;29:612-7.

3. Meyer A, Meyer N, Schaeffer M, et al. Incidence and prevalence of inflammatory myopathies: a systematic review. Rheumatology 2015;54:50-63.

4. Hayes D, Baker PB, Mansour HM, et al. Interstitial lung disease in a child with antisynthetase syndrome. Lung 2013;191:441-3.

5. Cavagna L, Nuño L, Scirè CA, et al. Clinical spectrum time course in anti Jo-1 positive antisynthetase syndrome: results from an international retrospective multicenter study. Medicine 2015;94:e1144

6. Cox JT, Gullotti DM, Mecoli CA, et al. "Hiker's feet": a novel cutaneous finding in the inflammatory myopathies. Clin Rheumatol 2017;36:1683-6.

7. WernhamM, MontagueSJ. Mechanic's Hands and hiker's feet in antisynthetase syndrome. CMAJ 2017;189:E1365.

8. Neri R, Barsotti S, Simone B, et al. Cancer-associated myositis: A 35-year retrospective study of a monocentric cohort. Rheumatol Int 2014;34:565-9.

9. Qiang JK, Kim WB, Baibergenova A, et al. Risk of malignancy in dermatomyositis and polymyositis. $J$ Cutan Med Surg 2017;21:131-6

10. Dobloug GC, Svensson J, Lundberg IE, et al. Mortality in idiopathic inflammatory myopathy: results from a Swedish nationwide population-based cohort study. Ann Rheum Dis 2018;77:40-7.

11. Alemo Munters L, Dastmalchi M, Katz A, et al. Improved exercise performance and increased aerobic capacity after endurance training of patients with stable polymyositis and dermatomyositis. Arthritis Res Ther 2013;15.

12. Woolf $\mathrm{SH}$, Grol R, Hutchinson A, et al. Clinical guidelines: potential benefits, limitations, and harms of clinical guidelines. $B M J$ 1999;318:527-30.

13. Institute of Medicine (US) Committee on Standards for Developing Trustworthy Clinical Practice Guidelines, 2011. Clinical practice guidelines we can trust. Washington (DC): National Academies Press (US). Available: http://www.ncbi.nlm.nih.gov/books/NBK209539/ [Accessed 30 Aug 2018].

14. Enk $A H$, Hadaschik EN, Eming R, et al. European guidelines (S1) on the use of high-dose intravenous immunoglobulin in dermatology. $J$ Eur Acad Dermatol Venereol 2016;30:1657-69.

15. AlexandersonH, LundbergIE. Disease-specific quality indicators, outcome measures and guidelines in polymyositis and dermatomyositis. Clin Exp Rheumatol 2007;25(6 Suppl 47):153-8.

16. BrilV, AllenbyK, MidroniG. IGIV in neurology-evidence and recommendations. Can J Neurol Sci J Can Sci Neurol 1999;26:139-52.

17. Donofrio PD, Berger A, Brannagan TH, et al. Consensus statement: the use of intravenous immunoglobulin in the treatment of neuromuscular conditions report of the AANEM ad hoc committee. Muscle Nerve 2009;40:890-900.

18. Doria A, laccarino L, Ghirardello A, et al. Pregnancy in rare autoimmune rheumatic diseases: UCTD, MCTD, myositis, systemic vasculitis and Beçhet disease. Lupus 2004;13:690-5.

19. Drake LA, Dinehart SM, Farmer ER, et al. Guidelines of care for dermatomyositis. J Am Acad Dermatol 1996;34:824-9.

20. Enders FB, Bader-Meunier B, Baildam E, et al. Consensus-based recommendations for the management of juvenile dermatomyositis. Ann Rheum Dis 2017;76:329-40.

21. Feasby T, Banwell B, Benstead T, et al. Guidelines on the use of intravenous immune globulin for neurologic conditions. Transfus Med Rev 2007;21(2 Suppl 1):S57-S107.

22. Fujimoto M, Asano $\mathrm{Y}$, Ishii $\mathrm{T}$, et al. The wound/burn guidelines - 4: Guidelines for the management of skin ulcers associated with connective tissue disease/vasculitis. J Dermatol 2016;43:729-57.

23. HengstmanGJD, van den HoogenFHJ, van EngelenBGM. Treatment of the inflammatory myopathies: update and practical recommendations. Expert Opin Pharmacother 2009;10:1183-90.

24. Huber AM, Kim S, Reed AM, et al. Childhood arthritis and rheumatology research alliance consensus clinical treatment plans 
for juvenile dermatomyositis with persistent skin rash. J Rheumatol 2017:44:110-6.

25. HuberAM, GianniniEH, BowyerSL, et al. Protocols for the initial treatment of moderately severe juvenile dermatomyositis: results of a Children's Arthritis and Rheumatology Research Alliance Consensus Conference. Arthritis Care Res 2010;62:219-25.

26. Huber AM, Robinson AB, Reed AM, et al. Consensus treatments for moderate juvenile dermatomyositis: beyond the first two months. Results of the second childhood arthritis and rheumatology research alliance consensus Conference. Arthritis Care Res 2012;64:546-53.

27. Kim S, Kahn P, Robinson AB, et al. Childhood arthritis and rheumatology research alliance consensus clinical treatment plans for juvenile dermatomyositis with skin predominant disease. Pediatr Rheumatol 2017;15.

28. Morisset J, Johnson C, Rich E, et al. Management of MyositisRelated interstitial lung disease. Chest 2016;150:1118-28.

29. Patwa HS, Chaudhry V, Katzberg H, et al. Evidence-based guideline: intravenous immunoglobulin in the treatment of neuromuscular disorders: report of the Therapeutics and Technology Assessment Subcommittee of the American Academy of Neurology. Neurology 2012;78:1009-15

30. RiderLG, GianniniEH, BrunnerHI, et al. International consensus on preliminary definitions of improvement in adult and juvenile myositis. Arthritis \&Rheumatism 2004;50:2281-90.

31. Sunderkötter C, Nast A, Worm M, et al. Guidelines on dermatomyositis - excerpt from the interdisciplinary S2k guidelines on myositis syndromes by the German Society of Neurology. JDDG: Journal der Deutschen Dermatologischen Gesellschaft 2016;14:321-38

32. Titulaer MJ, Soffietti R, Dalmau J, et al. Screening for tumours in paraneoplastic syndromes: report of an EFNS Task Force. Eur J Neurol 2011;18:19-e3.

34. MecoliCA, ParkJK, AlexandersonH, et al. Perceptions of patients, caregivers, and healthcareproviders of idiopathicinflammatorymyopathies: aninternational OMERACT study. $J$ Rheumatol.

35. Suzuki S, Hayashi YK, Kuwana M, et al. Myopathy associated with antibodies to signal recognition particle: disease progression and neurological outcome. Arch Neurol 2012;69:728-32.

36. Lefèvre $\mathrm{G}$, Meyer $\mathrm{A}$, Launay $\mathrm{D}$, et al. Seronegative polyarthritis revealing antisynthetase syndrome: a multicentre study of 40 patients. Rheumatology 2015;54:927-32.
37. CavagnaL, CastañedaS, SciréC, et al. Antisynthetase syndrome or what else? different perspectives indicate the need for new classification criteria. Ann Rheum Dis.

37. Hilton-JonesD. Myositis mimics: how to recognize them. Curr Opin Rheumatol 2014;26:663-70.

39. LundberglE, TjärnlundA, BottaiM, et al. European League against Rheumatism/American College of rheumatology classification criteria for adult and juvenile idiopathic inflammatory myopathies and their major subgroups. Ann Rheum Dis 2017;2017:1955-64.

39. CastañedaS, CavagnaL, González-GayMA. Comments on the "2017 Classification Criteria for Adult and Juvenile Idiopathic Inflammatory Myopathies and Their Major Subgroups". Points of concern. Arthritis Rheumatol Hoboken NJ.

40. CastañedaS, CavagnaL, González-GayMA. New criteria needed for antisynthetase syndrome. JAMA Neurol 2018;75:258-9.

42. Scirè CA, Gonzalez-Gay MA, Selva-O'Callaghan A, et al. Clinical spectrum time course of interstitial pneumonia with autoimmune features in patients positive for antisynthetase antibodies. Respir Med 2017;132:265-6.

42. THO, BrumfieldKA, HoskinTL, et al. Dysphagia in inflammatorymyopathy: clinical characteristics, treatment strategies, and outcome in 62 patients. Mayo Clin Proc 2007;82:441-7.

44. Danieli MG, Gelardi C, Guerra F, et al. Cardiac involvement in polymyositis and dermatomyositis. Autoimmun Rev 2016;15:462-5.

45. Diederichsen LP, Simonsen JA, Diederichsen AC, et al. Cardiac abnormalities in adult patients with polymyositis or dermatomyositis as assessed by noninvasive modalities. Arthritis Care Res 2016;68:1012-20.

46. Aggarwal R, Rider LG, Ruperto N, et al. 2016 American College of Rheumatology/European League against rheumatism criteria for minimal, moderate, and major clinical response in adult dermatomyositis and polymyositis: an international myositis assessment and clinical studies Group/Paediatric rheumatology international trials organisation collaborative initiative. Ann Rheum Dis 2017;76:792-801.

47. Rider LG, Aggarwal R, Pistorio A, et al. 2016 American College of Rheumatology/European League against rheumatism criteria for minimal, moderate, and major clinical response in juvenile dermatomyositis: an international myositis assessment and clinical studies Group/Paediatric rheumatology international trials organisation collaborative initiative. Ann Rheum Dis 2017;76:782-91.

48. MurraySG, SchmajukG, TrupinL, et al. A population-based study of infection-related hospital mortality in patients with dermatomyositis/ polymyositis. Arthritis Care Res 2015;67:673-80. 
Correction: Idiopathic inflammatory myopathies: narrative review of unmet needs in clinical practice guidelines

Meyer A, Scirè CA, Talarico R, et al. Idiopathic inflammatory myopathies: narrative review of unmet needs in clinical practice guidelines. RMD Open 2019;4:e000784. doi: 10.1136/rmdopen-2018-000784

This article has been corrected since it first published. The authors would like to notify that title of the article has been changed to:

Idiopathic inflammatory myopathies: state of the art on clinical practice guidelines

Open access This is an open access article distributed in accordance with the Creative Commons Attribution Non Commercial (CC BY-NC 4.0) license, which permits others to distribute, remix, adapt, build upon this work non-commercially, and license their derivative works on different terms, provided the original work is properly cited, any changes made are indicated, and the use is non-commercial. See: http://creativecommons.org/licenses/by-nc/4.0

(c) Author (s) (or their employer(s)) 2019. Re-use permitted under CC BY-NC. No commercial re-use. Published by BMJ.

RMD Open 2019;5:e000784corr1. doi:10.1136/rmdopen-2018-000784corr1

D) Check for updates 